\title{
Scintillometer Device
}

National Cancer Institute

\section{Source}

National Cancer Institute. Scintillometer Device. NCI Thesaurus. Code C50062.

A device designed to measure radioactivity indirectly by its ability to cause flashes of light in a sensitive material. 